\title{
Low-dose insulin treatment of hyperosmolar diabetic coma
}

\author{
A. D. WRIGHT \\ M.B., F.R.C.P. \\ M. G. FitzGERALD \\ M.D., F.R.C.P.
}

C. H. WALSH

M.D., M.R.C.P.

J. M. Malins

M.D., F.R.C.P.

The Diabetic Clinic, The General Hospital, Steelhouse Lane, Birmingham B4 6NH

\begin{abstract}
Summary
The effect of low-dose hourly i.m. injections of insulin has been studied in the treatment of 17 episodes of hyperosmolar non-ketoacidotic diabetic coma compared with 26 episodes of hyperosmolar ketoacidosis occurring in patients over $\mathbf{4 0}$ years of age. The fall in blood sugar was satisfactory in the majority of episodes of both types of coma and there was no evidence that patients with hyperosmolar nonketoacidotic coma were more sensitive to insulin. The excess mortality in the non-ketotic group (47\%) compared with the ketoacidotic group (16\%) was not due to uncontrolled diabetes.
\end{abstract}

\section{Introduction}

Recognition of non-ketoacidotic hyperosmolar diabetic coma and interest in its management has increased remarkably in recent years. The disorder is characteristically found in middle-aged and elderly patients, and it is associated with a mortality of $40-70 \%$ in some series (Arieff and Carroll, 1972). Controversy still exists on the optimal form of management for this condition. It has been suggested that patients suffering from the disorder are more sensitive to insulin than are patients in ketoacidosis. With the development of a simplified, successful regimen using low-dose insulin for the management of diabetic ketoacidosis (Alberti, Hockaday and Turner, 1973), it seemed a natural extension to evaluate this form of management in non-ketoacidotic hyperosmolar patients. In a few such patients low-dose intravenous insulin infusions have been reported (Bendezu et al., 1978; Keller and Berger, 1980). The authors now report the results of a study in which they treated non-ketoacidotic hyperosmolar patients with a low-dose intramuscular insulin regime, and compare their results with those in a similar group of patients with hyperosmolar ketoacidosis.

\section{Methods}

All episodes of uncontrolled diabetes requiring i.v. fluid replacement occurring in patients over $40 \mathrm{r}$ years of age admitted to the General Hospital over 30 successive years were selected for analysis if the calculated serum osmolality $\left(2\left(\mathrm{Na}^{+}+\mathrm{K}^{+}\right)+\right.$urea $+\mathrm{G}$ glucose in mmol/l) on admission was $\geqslant 340 \mathrm{mmol} / \rho$ kg. Two episodes of proved ketoacidosis were excluded because the initial serum biochemistry was insufficient to calculate the osmolality and 3 episodesp of proved hyperosmolar ketoacidosis were exclude because i.v. insulin had been used. In all the 5 episodes excluded, the outcome was satisfactory. 믐 The 43 episodes ( 40 patients) of hyperosmolar co:日a were divided into 2 groups according to the degreeo of ketoacidosis:

(1) hyperosmolar non-ketoacidosis; 17 episo đê. occurring in 15 patients ( 5 male, mean age 67 years, 10 female, mean age 73 years) fell into one of the following categories on admission:

(a) no ketonuria (ketostix) and serum bicarbonate $>17.5 \mathrm{mmol} / \mathrm{l}$ (4 episodes);

(b) ketonuria + or ++ and serum bicarbonate $>\frac{3}{3}$ $17.5 \mathrm{mmol} / \mathrm{l}$ (13 episodes).

Four of the patients were West Indian (2 sickle़ trait-positive) and one Indian. Seven of the patients had known hypertension with diastolic BP $>95$. $\mathrm{mmHg}$.

(2) Hyperosmolar ketoacidosis; 26 episodes occurring in 25 patients (12 male, mean age $6 ळ$ years; 13 female, mean age 64 years) had ketonuria ++ or +++ , plasma ketostix positive or the characteristic odour of acetone on breath was present and serum bicarbonate $\leqslant 17.5 \mathrm{mmol} / 1$ or admission. All patients were Caucasian and 3 hado hypertension.

The clinical details of the patients on admission are shown in Table 1. In all episodes there was some impairment of consciousness but no focal neuro logical signs apart from one patient with a stroke that had occurred before the onset of coma. Venous్ blood was taken on admission for blood sugar (ferricyanide method), serum sodium, potassiump and urea and capillary blood for $\mathrm{pH}$ and bicarbonate 
TABLE 1. Clinical details on admission

\begin{tabular}{|c|c|c|c|c|}
\hline & \multicolumn{2}{|c|}{ Non-ketosis } & \multicolumn{2}{|c|}{ Ketoacidosis } \\
\hline & $n$ & $(\%)$ & $n$ & $(\%)$ \\
\hline$\overline{\text { Episodes }}$ & 17 & & 26 & \\
\hline Newly diagnosed diabetes & 4 & (24) & 2 & (8) \\
\hline Infection & 8 & (47) & 9 & (35) \\
\hline Hypotension (systolic $\mathrm{BP}<100 \mathrm{mmHg}$ ) & 2 & (12) & 5 & (19) \\
\hline Hypothermia $\left(<36^{\circ} \mathrm{C}\right)$ & 8 & (47) & 16 & (62) \\
\hline \multicolumn{5}{|l|}{ Level of unconsciousness: } \\
\hline drowsy & 7 & & 12 & \\
\hline response to verbal commands. Very drowsy & 5 & & 5 & \\
\hline response to painful stimuli only & 4 & & 5 & \\
\hline unresponsive & 1 & & 3 & \\
\hline stroke & - & & 1 & \\
\hline
\end{tabular}

(Astrup). Repeat measurements were made at various time intervals after insulin was started and the data standardized by taking the actual or expected (where measurements were available shortly before and after $6 \mathrm{hr}$ ) results at $6 \mathrm{hr}$ for comparison. The time taken for the blood sugar concentration to reach $<14 \mathrm{mmol} / \mathrm{l}$ was also estimated. Subsequent falls in blood glucose have not been analysed be- cause i.v. fluid was changed to $5 \%$ dextrose and insulin given 4 hourly subcutaneously. All patients were managed by the staff of the diabetic clinic and treatment was consistent throughout the study (Soler et al., 1975) using 0.9\% sodium chloride initially or $0.45 \%$ if hypernatraemic. Intravenous bicarbonate was given in 11 episodes of ketoacidosis and in one patient with non-ketoacidosis following

TABLE 2. Biochemical details on admission

\begin{tabular}{lccc}
\hline & $\begin{array}{c}\text { Non-ketoacidotic } \\
\text { mean }\end{array}$ & $\begin{array}{c}\text { Ketoacidotic } \\
\text { mean }\end{array}$ & \\
\hline & $( \pm$ s.e. mean $)$ & $( \pm$ s.e. mean $)$ & $P$ \\
Blood sugar $(\mathrm{mmol} / \mathrm{l})$ & $51(3.4)$ & $53(2 \cdot 4)$ & $\mathrm{NS}$ \\
Serum urea $(\mathrm{mmol} / \mathrm{l})$ & $26(2 \cdot 5)$ & $19(1 \cdot 2)$ & $<0.01$ \\
Serum Na $+(\mathrm{mmol} / \mathrm{l})$ & $147(3 \cdot 7)$ & $137(1 \cdot 6)$ & $<0.01$ \\
Serum K+ $(\mathrm{mmol} / \mathrm{l})$ & $4 \cdot 7(0.18)$ & $5 \cdot 8(0.27)$ & $<0.01$ \\
Calculated serum osmolality (mmol/kg) & $381(8)$ & $358(2 \cdot 4)$ & $<0.01$ \\
\hline
\end{tabular}

$P=$ difference between non-ketosis and ketoacidosis episodes using Student $t$-test; NS $=$ not significant.

TABLE 3. Treatment and blood sugar response

\begin{tabular}{|c|c|c|c|}
\hline & Non-ketosis & Ketoacidosis & $P$ \\
\hline $\begin{array}{l}\text { Intravenous fluid (litre) } \\
0-6 \mathrm{hr} \\
0-24 \mathrm{hr}\end{array}$ & $\begin{array}{l}2.9(0.18) \\
6.9(0.44)\end{array}$ & $\begin{array}{l}3 \cdot 8(0 \cdot 18) \\
7 \cdot 4(0 \cdot 23)\end{array}$ & $\begin{array}{l}<0.01 \\
\text { NS }\end{array}$ \\
\hline $\begin{array}{l}\text { Potassium chloride } \\
\text { mmol in } 0-6 \mathrm{hr}\end{array}$ & $150(13)$ & $183(11)$ & NS \\
\hline $\begin{array}{l}\text { Soluble insulin (Actrapid) } \\
\text { units in } 0-6 \mathrm{hr} \\
\text { units in } 0-24 \mathrm{hr}\end{array}$ & $\begin{array}{c}48(3 \cdot 9) \\
119(11 \cdot 3)\end{array}$ & $\begin{array}{r}52(2 \cdot 9) \\
129(8 \cdot 6)\end{array}$ & $\begin{array}{l}\text { NS } \\
\text { NS }\end{array}$ \\
\hline $\begin{array}{l}\text { Fall in blood sugar } \\
\text { mmol/1 in } 0-6 \mathrm{hr} \\
\% \text { change } 0-6 \mathrm{hr} \\
\text { time (hr) taken to reach } 14 \mathrm{mmol} / 1 \\
(n)\end{array}$ & $\begin{array}{l}19 \cdot 5(2 \cdot 6) \\
39 \cdot 2 \\
15 \cdot 5(1 \cdot 7) \\
(13)\end{array}$ & $\begin{array}{l}24 \cdot 5(2 \cdot 3) \\
46 \cdot 6 \\
14(1 \cdot 0) \\
(24)\end{array}$ & $\begin{array}{l}\text { NS } \\
\text { NS } \\
\text { NS }\end{array}$ \\
\hline
\end{tabular}

Results are expressed as mean ( \pm s.e. mean); $P=$ difference between non-ketosis and ketoacidosis using Student $t$-test; NS not significant. 
a cardiac arrest. Soluble insulin (Actrapid) was given i.m. using 6-10 u./hr after an initial loading dose of 10 (32 episodes) or 20 units (11 episodes).

\section{Results}

The initial blood sugar concentrations were not significantly different but the serum sodium and urea and hence osmolality were higher and more variable in the non-ketotic group (Table 2). Fluid replacement was similar in both groups of patients except the mean initial rate of replacement was slower in the non-ketotic group (Table 3). The total amount of i.v. potassium chloride and i.m. insulin administered was similar in the 2 groups.

The initial rate of fall of blood sugar and the time taken to fall below $14 \mathrm{mmol} / \mathrm{l}$ were not significantly different in the 2 groups of patients (Table 3 ). In the episodes of ketoacidosis the fall of blood sugar in the first $6 \mathrm{hr}$ correlated with the initial blood sugar $(r=+0.64, P<0.01)$ but not in the episodes of nonketotic coma $(r=+0 \cdot 27, P>0 \cdot 05)$. The absolute or percentage fall in blood sugar at $6 \mathrm{hr}$ was not different in the patients with infection, hypotension or hypothermia on admission and was not affected by the initial insulin dose or when i.v. bicarbonate was used in the ketoacidosis group. There was no relationship of the fall in blood sugar to the initial or $6 \mathrm{hr}$ serum sodium or to the initial serum urea concentrations.

A satisfactory outcome with the patient leaving hospital occurred in $50 \%$ of the episodes of nonketosis (Table 4). No deaths occurred from uncontrolled diabetes alone. The high mortality in the non-ketosis group was due to deaths occurring after a satisfactory metabolic response had been achieved. The metabolic disturbance probably contributed to 2 of these late deaths due to acute renal failure and pulmonary embolism but none of the early deaths. The metabolic disturbance probably contributed to one of the early deaths in ketoacidosis, the patient dying with severe pyelonephritis one hr after admission, but to none of the late deaths.

\section{Discussion}

A precise clinical and biochemical definition of $c$. non-ketotic hyperosmolar coma is not possible and $\overrightarrow{\vec{F}}$ the authors appreciate the choice of certain limits $\stackrel{5}{?}$ of plasma bicarbonate and serum osmolality is? arbitrary. The aim was to exclude significant ketosis $\frac{\bar{\sigma}}{\overline{0}}$ and acidosis and to include significant hyperos- $\frac{\rho}{\sigma}$ molality. A calculated serum osmolality of $340 \AA$ $\mathrm{mmol} / \mathrm{kg}$ is likely to underestimate the true osmolality (Tomkins and Dormandy, 1971). The clinical $\vec{\circ}$ findings in the non-ketoacidotic group are similar ${ }_{-}^{\circ}$ to other reported series, i.e. an excess of newly $\vec{\omega}$ diagnosed diabetic patients (Danowski and Nabarro, $\frac{\circ}{8}$ 1965), West Indian origin (Pyke, 1969) and hyper-80 tension (Gerich, Martin and Recant, 1971), but the 3 . present authors did not discover any episode $v$ following recent introduction of drugs known to precipitate hyperosmolar, non-ketotic coma. Twopatients in both groups were taking thiazide diure-ज tics at the time of admission, making this an un- $)$ likely cause of the lower initial serum potassium level in the non-ketotic group. A low or normal $\vec{\omega}$ serum potassium on admission has been noted in $\mathbb{D}$ several other reports, emphasizing the need for $\frac{\vec{D}}{\mathbb{D}}$ early and adequate i.v. potassium chloride therapy 3 regardless of the particular insulin method Ф્థ (Podolsky, 1978).

In diabetic coma, the rate of fall of blood glucose $\infty$ is due to two main factors-rehydration and insula. effect. Fluid replacement alone may result in a mean fall of $1.1 \mathrm{mmol} / \mathrm{l} / \mathrm{hr}$ (Waldhäusl et al., 1979). S Alberti et al. (1973) found a mean fall of $2.9 \mathrm{mmol} / 1$ 응 before the first dose of i.m. insulin was given but once insulin had been started the rate increased to $\propto$ $5 \cdot 1 \mathrm{mmol} / \mathrm{l}$ over the next $4 \mathrm{hr}$.

The blood sugar concentrations in the present $\stackrel{\circ}{3}$ patients during the first $6 \mathrm{hr}$ of therapy showed a satisfactory fall in both the non-ketoacidotic group? (mean fall $3.3 \mathrm{mmol} / \mathrm{l} / \mathrm{hr}$ ) and the ketoacidotic group (mean fall $4.1 \mathrm{mmol} / \mathrm{l} / \mathrm{hr}$ ). It is possible that 3 . the slightly slower blood sugar response seen in the $\dot{\sigma}$ non-ketoacidotic group was due to the slower rate of rehydration.

TABLE 4. Outcome of low-dose insulin treatment of patients with hyperosmolar diabetic coma

\begin{tabular}{|c|c|c|c|c|}
\hline & \multicolumn{2}{|c|}{ Non-ketosis } & \multicolumn{2}{|c|}{ Ketoacidosis } \\
\hline & $n$ & ( $\%$ of episodes) & $n$ & $(\%)$ \\
\hline Satisfactory & 9 & (53) & 22 & (84) \\
\hline Death within $48 \mathrm{hr}$ of admission & 1 & (6) & 2 & (8) \\
\hline Death 2-21 days after admission & 7 & (41) & 2 & (8) \\
\hline \multicolumn{5}{|l|}{ Major complications in fatal cases: } \\
\hline pyelonephritis & 3 & & 1 & \\
\hline bronchopneumonia & 1 & & - & \\
\hline myocardial infarct & 1 & & 2 & \\
\hline pulmonary embolism & 1 & & - & \\
\hline stroke & 1 & & 1 & \\
\hline acute renal failure & 1 & & - & \\
\hline
\end{tabular}


While the metabolic response using the low-dose i.m. regimen was satisfactory, the initial response of blood sugar during the first $6 \mathrm{hr}$ was poor in a few episodes of both types of coma. A poor response of $<2 \mathrm{mmol} / \mathrm{l} / \mathrm{hr}$ fall in blood sugar over the first $6 \mathrm{hr}$ was seen in 4 episodes of non-ketoacidosis and 4 episodes of ketoacidosis. This could not be related to any of the measures of severity of the coma nor to the rate of fluid replacement in the first $6 \mathrm{hr}$. Provided a fall in blood sugar has been demonstrated and the clinical state of the patient does not deteriorate the authors would not normally recommend changing the insulin protocol during the initial $6 \mathrm{hr}$ of treatment. The optimum speed of metabolic response is unknown. A slow steady metabolic response may be advantageous (Clements, Prockop and Winegrad, 1968) in attempting to avoid cerebral oedema, although this is a relatively uncommon complication of non-ketotic coma (Arieff and Carroll, 1974). The present results suggest that patients with hyperosmolar nonketoacidotic coma are no more sensitive to insulin than those in ketoacidosis.

Many authors have found a high mortality in nonketotic hyperosmolar coma. The present finding of $47 \%$ mortality per episode $(53 \%$ per patient) is similar to that of Arieff and Carroll (1972) where a mortality of $63 \%$ occurred in a series of 37 cases, but in most instances death was due to severe concurrent illness. Few authors, however, have compared the mortality of non-ketotic coma with episodes of ketoacidosis of similar age. It is known that a higher mortality occurs in the elderly in ketoacidosis (Barnett, Wilcox and Marble, 1962; Solar et al., 1973). The $16 \%$ mortality in the hyperosmolar ketoacidotic patients in the present study is not surprising in view of the age and the severity of the condition selected for study, but cannot be compared directly with the non-ketotic group whose mean age was even greater. Analysis of the causes of death in both the non-ketotic and ketoacidotic groups does not show a particularly high percentage of thrombotic problems as illustrated by a number of case reports (Whelton, Walde and Havard, 1971; Nicholson and Tomkin, 1974; Timperley, Preston and Ward, 1974) and on present evidence the authors would not recommend routine heparin treatment for all episodes of hyperosmolar coma.

\section{Acknowledgments}

Dr B. Northam and the staff of the Clinical Chemistry
Department of the General Hospital kindly made all the biochemical measurements. We are grateful to Dr Malcolm Nattrass for helpful comments.

\section{References}

Alberti, K.G.M.M., Hockaday, T.D.R. \& TURner, R.C. (1973) Small doses of intramuscular insulin in the treatment of diabetic coma. Lancet, ii, 515.

AriefF, A.I. \& Carroll, H.J. (1972) Non-ketotic hyperosmolar coma with hyperglycemia: clinical features, pathophysiology, renal function, acid-base balance, plasmacerebrospinal fluid equilibria and the effects of therapy in 37 cases. Medicine, 51, 73.

AriefF, A.I. \& Carroll, H.J. (1974) Cerebral edema and depression of sensorium in nonketotic hyperosmolar coma. Diabetes, 23, 525.

Barnett, D.M., Wilcox, D.S. \& Marble, A. (1962) Diabetic coma in persons over 60. Geriatrics, 17, 327.

Bendezu, R., Wieland, R.G., Furst, B.H., Mandel, M. \& GeNUTH, S.M. (1978) Experience with low-dose insulin infusion in diabetic ketoacidosis and diabetic hyperosmolality. Archives of Internal Medicine, 138, 60.

Clements, R.S., Prockop, L.D. \& Winegrad, A.l. (1968) Acute cerebral oedema during treatment of hyperglycaemia. An experimental model. Lancet, ii, 384.

Danowski, T.S. \& NABARRo, J.D.N. (1965) Hyperosmolar and other types of non-ketoacidotic coma in diabetes. Diabetes, 14, 162.

Gerich, J.E., Martin, M.M. \& Recant, L. (1971) Clinical and metabolic characteristics of hyperosmolar nonketotic coma. Diabetes, 20, 228.

Keller, U. \& Berger, W. (1980) Prevention of hypophosphatemia by phosphate infusion during treatment of diabetic ketoacidosis and hyperosmolar coma. Diabetes, 29, 87.

Nicholson, G. \& Tomkin, G.H. (1974) Successful treatment of disseminated intravascular coagulopathy complicating diabetic coma. British Medical Journal, 4, 450.

PoDolsky, S. (1978) Hyperosmolar nonketotic coma in the elderly diabetic. Medical Clinics of North America, 62, 815.

PYKe, D.A. (1969) Diabetic ketosis and coma. Journal of Clinical Pathology, 22 (suppl. 2), 57.

Soler, N.G., Bennett, M.A., FitzGerald, M.G. \& Malins, J.M. (1973) Intensive care in the management of diabetic ketoacidosis. Lancet, i, 952.

Soler, N.G., Wright, A.D., FitzGerald, M.G. \& Malins, J.M. (1975) Comparative study of different insulin regimens in management of diabetic ketoacidosis. Lancet, ii, 1221.

Timperley, W.R., Preston, F.E. \& Ward, J.D. (1974) Cerebral intravascular coagulation in diabetic ketoacidosis. Lancet, i, 952.

Tomkins, A.M. \& Dormandy, T.L. (1971) Osmolal pattern during recovery from diabetic coma. Lancet, ii, 952.

Waldhäusl, W., Kleinberger, G., Korn, A., Dudczak, R., Bratusch-Marrain, P. \& Nowotny, P. (1979) Severe hyperglycemia: effects of rehydration on endocrine derangements and blood glucose concentration. Diabetes, 28 , 577.

Whelton, M.J., Walde, D. \& Havard, C.W.J. (1971) Hyperosmolar non-ketotic diabetic coma: with particular reference to vascular complications. British Medical Journal, 1, 85. 